\title{
Concentration Of The baculovirus Autographa californica M nucleopolyhedrovirus (AcMNPV) by ultrafiltration
}

Ronald Michalsky ${ }^{1,2}$, A. Lorena Passarelli ${ }^{3}$, Peter H. Pfromm¹, Peter Czermak ${ }^{1,2}$

${ }^{1}$ Department of Chemical Engineering and ${ }^{3}$ Division of Biology, Kansas State University, Manhattan, Kansas, 66506, U.S.A.

${ }^{2}$ University of Applied Sciences Giessen, Institute of Biopharmaceutical Technology, Giessen, Germany

Corresponding Author: e-mail: peter.czermak@tg.fh-giessen.de; phone: +49 641 309 2551; fax: +49 6413092553

Keywords: Autographa californica M nucleopolyhedrovirus, membrane filtration, virus concentration, downstream processing

This paper published as: Michalsky R., A. L. Passarelli, P. H. Pfromm, P. Czermak: Purification of the Baculovirus Autographa californica M Nucleopolyhedrovirus (AcMNPV) by Ultrafiltration, Desalination 250 (3) (2010) p. 1125-1127.

\section{Abstract}

Concentration and retention of a rod-shaped virus during tangential flow ultrafiltration (UF) was assessed to evaluate the potential of membrane-based downstream methods with advantages such as easy scale-up for industrial processes. A recombinant baculovirus of the non-spherical Autographa californica M nucleopolyhedrovirus (AcMNPV), vHSGFP, expressing egfp was filtered using polyethersulfone membranes ranging from 30 to $1000 \mathrm{kDa}$ molecular weight cut-off (MWCO). A 20-fold virus concentration was achieved when a membrane cut-off range of 100 to $1000 \mathrm{kDa}$ was tested. Fouling was observed and cake formation and pore plugging were postulated as concurrent causes with different impact depending on the MWCO. A reduction of virus concentration in the range of 2 to $5 \log$ units in the permeate was observed illustrating the potential of membrane-based virus filtration as a useful unit operation in downstream processing.

\section{Introduction}

Virus clearance is critical in pharmaceutical and biotechnological processes [1]. Downstream processing of viruses as products (e.g., viral vectors expressing genes for gene therapy) requires virus concentration and purification [2]. However, virus purification using sucrose or cesium chloride density 
centrifugation is time consuming and results in significant virus particle losses [2]. Pelleted viruses from centrifugation can be highly viscous and difficult to resuspend in solution [3]. Additionally, downstream processing of products possibly contaminated with viruses (e.g., human blood derived products and antibodies) requires suitable elimination steps regarding various viruses [3]. Therefore, evaluation and validation of alternative virus purification or virus removal methods such as UF are of interest since UF has advantages over other purification methods including low energy consumption, simplified scale-up, and no chemicals being introduced into the process [1].

Virus removal and/or concentration have been reported for some viruses $[2,4,5]$. The logarithmic titer reduction is in the range of 1 to 8.5 [4] and using UF, oncoretroviral vectors were concentrated 16 to 25 times [2]. Though, at this time no standardized validation protocol for membrane-based virus filtration exists and processing properties are specific to individual virus formulations [3, 4]. Thus, filtration of viruses that are of industrial interest has to be characterized to assess process efficiency and product yield.

AcMNPV has been widely used as foreign gene expression vector and was recently used to develop a vaccine against human papillomavirus [6]. The virus has attracted interest as a vector for gene therapy and is used as a potential insect biopesticide (e.g., as VPN80 [7] for cabbage and cotton cultivation). The rod-shaped budded virions (BV) (DNA genome, enveloped, $40 \times 300 \mathrm{~nm}$ in size) of AcMNPV, a baculovirus pathogen for lepidopteran insects, are used in cell culture [8]. Previously a study in regard to BV storage at $4{ }^{\circ} \mathrm{C}$, exposure to temperatures from 15 to $65{ }^{\circ} \mathrm{C}$, and to shear stress through stirring and pumping was carried out [3]. The study presented here demonstrates the filtration behavior of a BV solution when filtration parameters with insignificant impact on virus infectivity or particle size are used.

\section{Materials and Methods}

Production of AcMNPV particles

Cells of the IPLB-SF21-AE (SF-21) cell line (Invitrogen) adapted to Sf-900 II Serum Free Medium (SFM) $(\mathrm{pH} 6.1 ; 360 \mathrm{mOsmoles} / \mathrm{kg}$; protein-free; a typical insect medium [9] containing mainly amino acids, glucose, $\mathrm{CaCl}_{2}, \mathrm{MgCl}_{2}, \mathrm{KCl}$ and $\mathrm{MgSO}_{4}$; Invitrogen) were grown at $27^{\circ} \mathrm{C}$ in SFM supplemented with $5 \mathrm{mg} / \mathrm{l}$ gentamicin (Invitrogen) and passaged twice weekly. The virus vHSGFP is a recombinant of AcMNPV that contains the egfp controlled by the Drosophila heat shock protein 70 (hsp70) promoter [10]. vHSGFP was grown in TC-100 medium (Invitrogen) supplemented with 10\% FBS (Invitrogen) [3, 8]. 


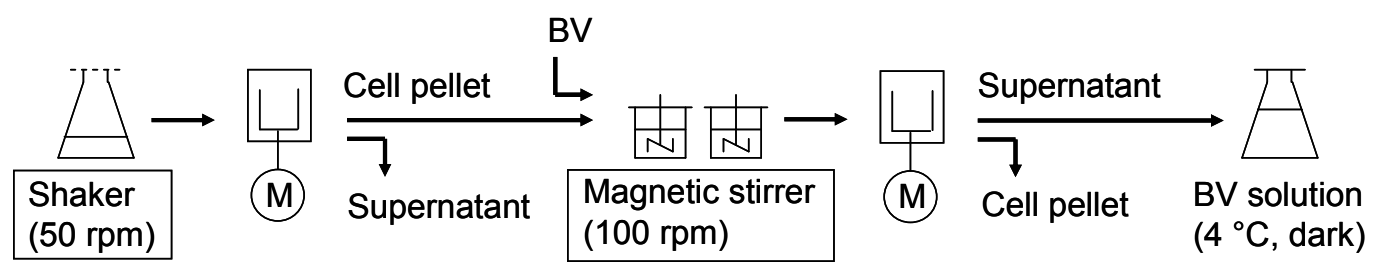

Figure 1: BV cultivation for ultrafiltration purposes (motor, $M$ ).

SF-21 cells were infected with vHSGFP in suspension culture at a multiplicity of infection (MOI) of 0.1 plaque forming units per cell (pfu/cell) [8]. BV in the supernatant was harvested 4 days post infection (p.i.) by centrifugation $(1000 \mathrm{x} \mathrm{g}$, $10 \mathrm{~min}$, at room temperature) and stored at $4{ }^{\circ} \mathrm{C}$ (Figure 1) [3, 8].

Ultrafiltration and in-process detection

A commercial ultrafiltration system (Sartoflow Slice 200 Benchtop, Sartorius) was used to concentrate BV solutions. Polyethersulfone (PES) flat sheet membranes $(30,50,100$ or $300 \mathrm{kDa}$ molecular weight cut-off (MWCO), respectively, $0.1 \mu \mathrm{m}$ pore size (which equates to about $1000 \mathrm{kDa}$, correlated using electron microscopy [11]); $19.5 \times 4.5 \mathrm{~cm}$ effective filter area, Sartocon Slice 200, Sartorius) were flushed before usage with $100 \mathrm{ml}$ water (purified with the Q-Gard 2 Purification Pack, Millipore Co.; demineralized; not de-gassed; autoclaved). The trans membrane pressure (TMP) and the trans membrane flux were logged during processing (WinWedge $® 32$ software, Pressure Sensor Connection Box and TE4101 balance, Sartorius). The flow parallel to the membrane was set to $150 \mathrm{ml} / \mathrm{min}[5,12]$. The feed vessel was equipped with BV solution $(500 \mathrm{ml})$ and samples (from the feed and permeate each with $1 \mathrm{ml}$ ) were collected at 100, 200, 300,400 and $450 \mathrm{ml}( \pm 10 \mathrm{ml})$ of solution that passed the filter and were stored at $4{ }^{\circ} \mathrm{C}$ in opaque containers. All filtration experiments were performed at room temperature $\left(\sim 25^{\circ} \mathrm{C}\right)$ and in duplicate. Membranes were cleaned by backflushing with water from the permeate to the feed $(10 \mathrm{~min}, 500 \mathrm{ml} / \mathrm{min})$, then incubated for $>24 \mathrm{~h}$ at $50{ }^{\circ} \mathrm{C}$ in sodium hydroxide $(1 \mathrm{~mol} / \mathrm{L}$, Fisher Scientific) and stored at $4{ }^{\circ} \mathrm{C}$ in a solution of sodium hydroxide $(0.1 \mathrm{~mol} / \mathrm{L})$ with an addition of 20 vol\% ethanol (Aaper Alcohol Co.) [5]. The pseudo-steady state flux of water was detected as a benchmark before virus filtration experiments. The PSF was taken when the flux loss was less than $1 \mathrm{ml} / \mathrm{min}$ during $5 \mathrm{~min}$ or more. Filtered BV solution was reused if no contamination and a viral titer $\sim 5 \times 10^{6} \mathrm{pfu} / \mathrm{ml} \pm 90 \%$ was present.

Virus infectivity

$\mathrm{TCID}_{50}$ endpoint dilution [8] based on the expression of the Green Fluorescent Protein by host cells infected with vHSGFP and an Eclipse TE200 microscope (green fluorescence emission filter, X200 magnification, Nikon) was utilized to assess the viral titer 5 days p.i. 


\section{Results and Discussion}

The course of infectivity in the retentate during filtration with membranes ranging from 30 to $1000 \mathrm{kDa}$ was determined using end-point dilution (Figure 2).
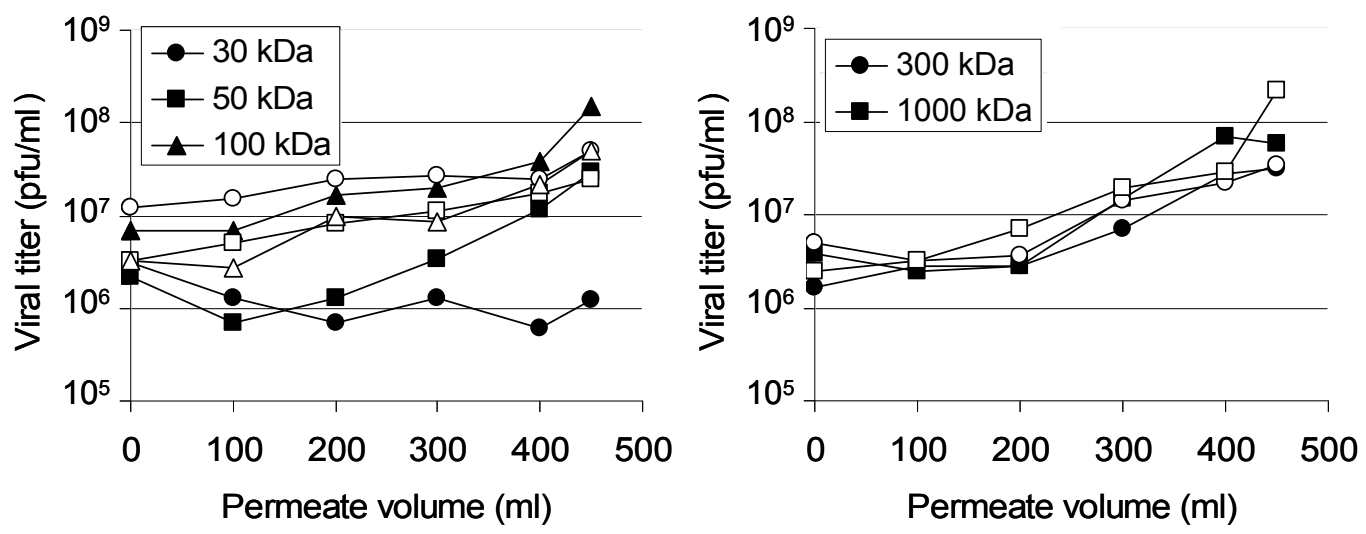

Figure 2: BV infectivity of retained solution versus the volume passing the membrane during filtration. The filtration system was equipped with $500 \mathrm{ml} \mathrm{BV}$ solution, operated at $150 \mathrm{ml} / \mathrm{min}$ volume flow parallel to the membrane and was stopped when $450 \mathrm{ml}$ passed the membrane. Virus titer was determined by endpoint dilution. Filtrations were done in duplicate (black symbols indicate the first run, repetitions post cleaning are shown using white symbols). Solid lines are added for visualization.

Considering the uncertainty of end-point dilution (0.5 log units [8]), the infectivity of $\mathrm{BV}$ solution retained using the $30 \mathrm{kDa}$ membrane was constant. In a halflogarithmic plot the course of infectivity using membranes ranging from 50 to 100 $\mathrm{kDa}$ was linear and had a lower slope compared to the use of a higher MWCO. Infectivity increased gradually to about +1 log unit. This might be due to BV partly accumulated in a thin cake layer in front of the membrane. Opposing the 300 and $1000 \mathrm{kDa}$ filters, viral concentration values initially remained constant and then increased linear with a higher slope, slightly higher values of the final concentration and with increased repeatability. Thus, assumed clogging of these membrane pores by BV appears to occur at early times of filtration followed by exponential accumulation of BV in the retentate. High values of viral concentration of about 20 times were archived using 100 to $1000 \mathrm{kDa}$ membranes. This is most likely due to a high ratio of particle average size to membrane pore size [3].

UF using the parameters described reduced infectivity in the range of 2 to 5 log units (Table 1). 
Table 1: Virus concentration in the permeate ${ }^{A}$

\begin{tabular}{|c|c|c|}
\hline \multirow[t]{2}{*}{ MWCO (kDa) } & \multicolumn{2}{|c|}{ Viral titer (pfu/ml) } \\
\hline & $1^{*}$ & $2^{*}$ \\
\hline 30 & $(1.9-5.7) \times 10^{4}$ & $\mathrm{~L}$ \\
\hline 50 & $(0.0-1.3) \times 10^{2}$ & $(2.4-6.9) \times 10^{4}$ \\
\hline 100 & L & $(0.1-3.2) \times 10^{2}$ \\
\hline 300 & $(0.7-2.8) \times 10^{4}$ & $(1.3-6.9) \times 10^{2}$ \\
\hline 1000 & $(1.7-3.7) \times 10^{5}$ & $(0.7-1.2) \times 10^{5}$ \\
\hline
\end{tabular}

A) were constant in the stated range.

*) Concentrations in six samples were determined in two independent filtration experiments for each membrane.

L) Below the limit of detection.

Values of the reduction were unordered and point presumably to the interaction between rod-shaped BV particles and the distribution of membrane pore size. Filtration of Aedes aegypti densonucleosisvirus (AeDNV) (spherical, $18-26 \mathrm{~nm}$ in size) decreased infectivity of permeate below the detection limit when a MWCO in the range of 30 to $100 \mathrm{kDa}$ was used. Concurrently, protein concentrations were reported to increase from about 3 to $6 \mathrm{mg} / \mathrm{ml}$ in the retentate and to remain constant $\sim 3 \mathrm{mg} / \mathrm{ml}$ in solution that passed through the membrane $[5,12]$. Since the initial protein concentration was 30 fold higher than it was detected in this study (data not shown), various scenarios including aggregation and different fouling mechanisms, dependent on size and shape of membrane pores and viruses, may explain the retention of AeDNV as opposed by BV that passed membranes ranging from 30 to $100 \mathrm{kDa}$ [13].

\section{Conclusions}

AcMNPV is a baculovirus with broad applications [6,7], including uses as a protein expression vector. However, the use of viruses for various applications is dependent on its purity and formulation. Membrane based virus filtration is widely used and advantageous in biotechnological and pharmaceutical downstream processing [12, 13], e.g., due to simplified scale-up [1].

In this study, BV of the baculovirus AcMNPV were successfully concentrated 20fold in a protein-free medium using UF with commercial flat-sheet PES membranes (100 to $1000 \mathrm{kDa}$ MWCO) at an average TMP of 0.15 bar and $\sim 25$ ${ }^{\circ} \mathrm{C}$. Membrane-based filtration appears to be a feasible unit operation in downstream processing of BV for example for industrial scale protein expression. Using membranes and filtration parameters as determined here, our results suggest that reduction of BV in filtered solutions to below detection limits can not be guaranteed using the protocol and the membranes tested here. However, 
filtration in the tested $\mathrm{MWCO}$ range led to reproducible reduction of BV concentration in the permeate by 2 to 5 log units compared to the unfiltered feed. Hence, membrane-based virus clearance from solutions is beneficial as a unit operation in biotechnological downstream processing since multi-step procedures are generally needed and membrane filtration can significantly reduce the presence of virus as an initial step to facilitate further processing.

\section{Acknowledgments}

Kent E. Hampton and Chris Lehiy are gratefully acknowledged for their technical assistance. This work was funded in part by the DAAD (German Academic Exchange Service) and by the Innovation Funds of the University of Applied Sciences Giessen-Friedberg.

\section{References}

[1] G. Belfort, R.H. Davis and A.L. Zydney. The behavior of suspensions and macromolecular solutions in crossflow microfiltration. Journal of Membrane Science 96 (1994)1-58.

[2] M.d.I.M. Segura, A. Kamen and A. Garnier. Downstream processing of oncoretroviral and lentiviral gene therapy vectors. Biotechnology Advances 24 (2006)321-337.

[3] R. Michalsky, P.H. Pfromm, P. Czermak, C.M. Sorensen and A.L. Passarelli. Effects of temperature and shear force on infectivity of the baculovirus Autographa californica M nucleopolyhedrovirus. Journal of Virological Methods (submitted 2008).

[4] H. Aranha. Viral clearance strategies for biopharmaceutical safety - Part

2: Filtration for viral clearance Biopharm. The Applied Technologies of Biopharmaceutical Development 14 (2001)32-43.

[5] D.L. Grzenia, J.O. Carlson, P. Czermak, B. Han, R. Specht and S.R. Wickramasinghe. Purification of Densonucleosis Virus by Tangential Flow Ultrafiltration. Biotechnology Progress 22 (2006)1346-1353.

[6] GlaxoSmithKline-Biologicals, S.A., Cervarix® product information, Human Papillomavirus Vaccine Types 16 and 18 (Recombinant, AS04 adjuvanted), Document approved by the Therapeutic Goods Administration, 2007.

[7] F. Moscardi. Assessment of the application of baculoviruses for control of lepidoptera. Annual Review of Entomology 44 (1999)257-289.

[8] D.R. O'Reilly, L.K. Miller and V.A. Luckow, (Eds.), Baculovirus expression vectors: A laboratory manual, Oxford University Press, New York, 1994.

[9] T. Lindl, (Ed.), Zell- und Gewebekultur, 5. Auflage, Spektrum Akademischer Verlag, Heidelberg, 2002.

[10] T.E. Clarke and R.J. Clem. Lack of involvement of haemocytes in the establishment and spread of infection in Spodoptera frugiperda larvae infected with the baculovirus Autographa californica $M$ 
nucleopolyhedrovirus by intrahaemocoelic injection. Journal of General Virology 83 (2002)1565-1572.

[11] Pall Corporation, Centrifugal Devices, Filtration. Separation. Solution. SM, 8/03, 5k, GN03.0785, PN 33327, 2003.

[12] P. Czermak, D. L. Grzenia, A. Wolf, J.O. Carlson, R. Specht, B. Han and S.R. Wickramasinghe. Purification of Densonucleosis Virus by Tangential Flow Ultrafiltration and by Ion Exchange Membranes. Desalination 224 (2008)23-27.

[13] P. Czermak, D. Nehring and S.R. Wickramasinghe. Membranfiltration in Animal Cell Culture, in R. Poertner (Ed.), Animal Cell Biotechnology: Methods and Protocols, 2nd Edition, Chapter 19, p. 397-420, Humana Press, Totoba USA, 2007, ISBN 978-1-58829-660-3. 